ARTICLE

DOI: $10.1057 /$ s41599-017-0006-3

\title{
Disrupting environmental crime at the local level: an operational perspective
}

\author{
Stoyan Barrett ${ }^{1} \&$ Rob White ${ }^{2}$
}

\begin{abstract}
The multi-dimensional nature of environmental crimes requires innovative means to combat them. This paper examines the nature and dynamics of one particular collaborative law enforcement approach directed at environmental crime. While much interest in multi-agency and multi-pronged approaches has been generated in recent years, especially as this pertains to environmental crime at the international and regional levels, this paper provides a detailed description of how this can occur at the local level. Based on a case study of nefarious activities relating to illegal waste management in Durham and surrounding areas (located in the North East of England), the paper emphasises the importance of 'disruption' as an important operational concept, and how inter-agency cooperation under skilled leadership and with clear purpose can lead to tangible enforcement outcomes. As the article demonstrates, particular agencies on their own have limited impact and do not always address the issue of how to take away an organised criminal group's ability to function. By contrast, multi-agency work enables authorities to work in a united front and thus to succeed in disrupting criminal activities causing environmental harm.
\end{abstract}

\footnotetext{
${ }^{1}$ Durham Police Constabulary, Durham, UK. ${ }^{2}$ School of Social Sciences-University of Tasmania, Hobart, TAS, Australia. Correspondence and requests for materials should be addressed to R.W. (email: r.d.white@utas.edu.au)
} 


\section{Introduction}

ne of the hallmarks of contemporary environmental crime is that such crime more likely than not involves 'convergence crime' (Pink and White, 2016; INTERPOL, 2015; INTERPOL and UNEP, 2016). This refers to how particular environmental offences, such as illegal disposal of waste and trafficking in wildlife, can also simultaneously be associated with other criminal offences or illegal activities, from bribery and corruption through to failure to have required permits. The multi-dimensional nature of environmental crimes, while complicating things, also opens the door to innovative means to combat them.

Moreover, the purposes of environmental law enforcement may be effectively served by measures other than prosecuting offenders directly for the offensive behaviour in question. For instance, in order to protect environments and preserve ecological integrity, it is sometimes more effective, from the point of view of environmental outcomes, to focus on disrupting crime in order to diminish its occurrence. In orienting towards 'disruption', it is possible to mobilise a number of tactics that impede the ability of offenders to function (Dighe and Pettus, 2011). This is a central theme of the present article. Reliance upon the formal processes of criminal justice including prosecution, conviction and sentencing, may be less important in this scenario than stopping or frustrating the offending by employment of other means.

Collaboration and partnerships are frequently touted as a key means of fighting organised criminal networks involved with diverse commodities and activities (Pink and White, 2016; Crawford and Cunningham, 2015). This paper examines the nature and dynamics of one particular collaborative law enforcement approach directed at disrupting environmental crime. While much interest in multi-agency and multi-pronged approaches has been generated in recent years, especially as this pertains to environmental crime at the international, national and regional levels, this paper provides a detailed description of how this can occur at the local level. Based on a case study of nefarious activities relating to illegal waste management in Durham, United Kingdom and surrounding areas, the paper emphases the importance of 'disruption' as an important operational concept, and how inter-agency cooperation under skilled leadership and with clear purpose can lead to tangible enforcement outcomes.

\section{Collaborative environmental law enforcement}

The initial importance of multi-agency networking and collaborative practices stems from simple economics, especially given the pressures for environmental law enforcement to improve at the same time as the need for it expands. The effectiveness of environmental law enforcement, particularly in the light of restricted budgets and under-resourced units, will very much depend upon how well partnerships are formed and strategies implemented, and the flexibility of interventions in the context of rapid social and ecological change.

Some of the limitations of conventional environmental law enforcement practices and procedures are well known by practitioners and academics alike. For example, in recent work undertaken at the University of Tasmania on the policing of the disposal of hazardous waste it was found that there was poor data management, limited data sharing, the absence of routine data analysis, barriers when it comes to prosecution of offenders, and uncertainty as to who is meant to police which types of waste (White and Heckenberg, 2011). Across Australia there are major complexities related to defining and classifying 'waste', and little crossdepartmental dialogue about intervention procedures and dealing with problems in achieving effective compliance and enforcement. Importantly, as is the case with much environmental prosecution generally (White, 2016), there are major issues when it comes to sentencing and penalties. In a nutshell, very often judges and magistrates do not seem to take environmental crime seriously, are inconsistent in their sentencing, and lack understanding of the implications of both the crimes and the impact of lenient sentencing in relation to these crimes.

All these factors point in the direction of substantial changes in operational practices if environmental law enforcement is to progress towards a more meaningful and powerful level of intervention. There is certainly the necessity for the development of closer working partnerships among diverse stakeholders, as well as development of better data analysis for the purposes of future planning and strategic intervention. Drawing out the 'big stick' is also required to support stronger enforcement approaches rather than relying upon weak and frequently ineffective compliance measures (such as on-the-spot fines).

To be effective, agencies need to be able to harness the cooperation and expertise of many different contributors and liaise with relevant partners at the local through to the international levels (Crawford, 2008). But what do we actually mean by terms such as 'partnership' and 'collaboration'? These can be understood in various ways.

In its most basic sense, collaboration simply refers to people or agencies working together for a shared purpose. However, the meaning and social processes pertaining to collaboration-inpractice can be complicated and variable. To illustrate this, consider the following example. Within a prison context, collaboration means that prison officers, therapeutic staff, senior managers, teachers, nurses and doctors, case managers and support staff work-that is, all of those who work within the institutional hierarchy-work in unison and with shared purpose around prisoner issues. Simultaneously, these staff need to be able to collaborate with the many outside persons coming into the prison, such as the drug and alcohol counsellors, the youth workers, representatives of welfare agencies and government bureaucracies, sex offender specialists and so on; that is, those who offer skills across institutional settings (White and Graham, 2010). These dimensions can easily be transposed into an environmental law enforcement context.

For example, to build capacity and capability, the activities and collaborations of environmental crime response agencies has tended to naturally occur around networks, which are geographically-based (for example, known transit points and destinations in Asia), discipline-based (for example, environmental prosecutors) and commodity-based (for example, wildlife)

\section{Table 1 Types of inter- and intra- agency collaboration}

\section{Horizontal}

- Issues relevant to a number of agencies

- Emphasis on 'something is being done'

For example, Police, Customs, National Security, Environmental Protection Agencies

\section{Vertical}

- Among employees within an institutional hierarchy

- Emphasis on 'how something is done'

For example, protocols for forensic environmental investigation processes

\section{Diagonal}

- Collaboration across the horizontal and vertical axis

- Emphasis on 'the way something is done'

For example, agency interactions by species, by region, by type of agency

Source: Pink and White, 2016 
(Pink and Bartel, 2015). Collaboration across these dimensions and involving these networks can be predominantly horizontal, vertical or diagonal. These different types of collaboration are summarised in Table 1. There is no fixed or usual way in which collaboration occurs-instead the collaboration takes its shape depending on a number of factors, including if and how various networks are constituted. What is clear though is that for environmental crime, collaboration matters (Pink and White, 2016).

Much of the literature on environmental enforcement and collaboration has focused on networks at the national and international levels. In regards to transnational environmental crime, the International Network of Environmental Compliance and Enforcement (INECE) provides a case in point, as does the Interpol Environmental Crimes Committee. Regional and national networks of enforcement personnel and regulatory agencies are further examples of grounded collaboration involving diverse sets of players (Faure et al., 2015).

Taking the lead in developing new forms of collaboration and active engagement, in 2012 INTERPOL established the National Environmental Security Taskforce (NEST) model (INTERPOL, 2012; Higgins and White, 2016). The NEST is conceptual framework where various representatives from a range of agencies come together to contribute and leverage from the groups collective skill sets in order to more effectively develop, coordinate and implement response measures. In the Asia-Pacific, the lead agencies in the development of the NEST were Australia and New Zealand, with the NEST model drawing heavily upon the New Zealand Wildlife Enforcement Group (WEG) model. The WEG approach saw police, customs and environmental officers organise themselves in a coordinated tri-agency arrangement to respond to wildlife crime (Pink G (2015) Personal Communication. [at the time of contact for this, Grant Pink was the Australian representative to the INTERPOL Environmental Crime Committee]).

At its most basic level, a NEST is a task force of a firmly established team of experts who work together to address specific issues. They are comprised of senior criminal investigators, criminal analysts, training officers, prosecutors, financial specialists, forensic experts and others, drawn from police, customs, environmental and other specialised enforcement agencies, and also involving non-government and regional organisations as appropriate.

This formal networking is essential in several different ways. It allows for sharing of ideas and information about 'best practice'. It enables participants to gain a perspective on environmental crimes that occur within specific local and regional contexts and those that are more global in scope. It fosters cross-agency cooperation and intelligence exchanges within specific national contexts (horizontal connections that bring together environmental protection authority, police, customs, and other agency personnel), as well as internationally (vertical connections that bring together national representatives from different parts of the world, including United Nations personnel).

However, while the work on collaboration and networking points in the right direction, and includes important critical commentary on the strengths and limitations of collaborative arrangements, it still largely deals with collaboration among law enforcement agencies. As discussed below, there is much to be gained, and learned from, those instances of collaboration that range further afield. Just as environmental crime converges with other crimes so, too, environmental law enforcement can incorporate a wide range of stakeholders and players. If the purpose or end in doing so is disruption of the harmful activity, then the benefits are clear.

Carnwell and Carson (2005) distinguish between 'partnerships' (who we are) and 'collaborations' (what we do). In so doing, they describe different types of partnership, ranging from those based on a particular project or particular social problem, through to ideological and ethical partnerships that involve shared perspectives and specific viewpoints. Collaboration is seen as the process of working together in a particular kind of partnership although it is only one of several methods of doing so. As will be demonstrated, collaboration is, as much as anything, dictated by circumstance and contingency. And a lot depends upon how it works at the local level.

The lucrative nature of transnational environmental crime combined with the complexity of the networks and commodity chains associated with it, means that developing an effective law enforcement response is particularly challenging. Typically, the organised criminal modus operandi is one characterised as being loose, transnational, motivated by singular purpose, and networks formed on an ad hoc basis. By contrast, the typical law enforcement modus operandi is tight, jurisdiction-based, informed by multiple institutional demands, and subject to formalised arrangements and agreements (White and Heckenberg, 2014). Translated into crime fighting at the local level, this means that effective crime disruption must be tuned into the vagaries of the specific crimes and specific criminal networks operating at this level.

It can be observed that environmental regulation and enforcement frequently only finds effective purchase within particular jurisdictions and national contexts. Thus, for example, new forms of intervention, such as 'environmental enforcement sweeps', are now being applied where a specific community faces multiple environmental burdens. Such sweeps involve the use of administrative, civil and criminal enforcement tools in tandem to address the problems in a comprehensive fashion (Dighe and Pettus, 2011). Factory pollution, for example, might be responded to by examination of the permit compliance history of companies, investigation of violations of different environmental laws, and involvement of multiple agencies alongside community input. This model seems to present an ideal method of responding to environmental problems. It is also precisely the kind of thinking that informs our case study.

\section{Local multi-agency intervention in Durham}

Research specifically on environmental crimes has pointed to the great variation in who participates in this criminal activity and how they do so (Ayling, 2013; Wyatt, 2013). Indeed, there is a conjunction of many different factors that go into why and how such activity takes place (Lemieux, 2014; Wellsmith, 2011; Pires and Moreto, 2011; Pires, 2012). This means that any response to specific types of illegal activities must be tailored to the circumstances within which they occur. It also implies that the notion of 'organised criminal networks' has to be interpreted widely, to capture the diversity of ways in which people interact with each other in particular actor networks. Moreover, distinctions need to be made between localised activity based upon subsistence and/or family ties and activity involving organised criminal gangs seeking large profits from international sales (Ayling, 2013; Von Essen et al., 2014).

The case study below identifies how Organised Crime Groups (OCG) can manipulate lawful processes by exploiting loopholes within these processes, for financial gain. Organised crime often manifests as legitimate business when really it is focussed on extracting as much profit as possible including from illegal activity. For present purposes, organised crime is defined as serious crime that is planned, coordinated and conducted by people working together on a continuing basis. Their motivation is often, but not always, financial gain. Individuals working together for criminal purposes are called an Organised Crime Group (National Crime Agency, 2017). 
In this instance, the Organised Criminal Group was mainly locally based, and involved several family members among others. The commission of the crimes occurred locally, and the harms, therefore, were felt most acutely at the local level. The criminal network had both publicly recognisable members and 'silent' members, as explained below. The crimes were intentional and organised. They knew perfectly well what they were doing.

Within the United Kingdom, the Environment Agency oversees waste management (Environment Agency, 2017). This activity consists of the monitoring of onsite working practices, investigation of air, water and land pollution, and the correct processing of all waste types. Its mandate includes recycling of waste as well as the production, transportation and disposal of waste. If we examine the traditional route path of a waste skip filled with mixed waste, then this contextualises the case study below. A full skip is usually collected and removed to a waste transfer station. Usually the waste station is industrial sized, has large capacity and has several employees. Here the waste is separated, with some removed for recycling, and the remainder is sieved further into an almost soil-like form. This product is considered less damaging to the environment and is considered suitable for landfill (and, accordingly, attracts a low tax rate).

Crime Particulars. A local skip hire company was formed as a legitimate business operating across Durham and Darlington situated within the North East of England. As a permitted company, their business involved the hire of a variety of skips, approximately 100 in total covering a large area of North East England and North Yorkshire. Their business was usually to private individuals but always on a cash basis. This provided the first opportunity for manipulation with the average skip costing approximately $£ 100$ per day.

Once the full skips were collected they would be returned to one of three industrial sized compounds where anything of any intrinsic value would be separated and sold for recycling while the remainder was stockpiled. The stockpiling of the waste was supposed to be sieved down to its most basic form and land filled at the lowest tax rate, approximately $\mathfrak{E} 5$ per tonne (by contrast, raw waste costs approximately $£ 120$ per tonne in landfill tax). This provided the second area of manipulation.

Initially nothing appeared untoward and of no concern for the lead response agency, the UK Environment Agency, as any manipulation was in its infancy and undetected. However, as the sites began to fill it became abundantly obvious that the processing and removal of the waste was not being completed as agreed within the permits.

The Environment Agency began enquiries in 2008 when concerns were raised about the scale of unprocessed waste evident across the sites. The initial response was to offer assistance and request compliance, rather than proceeding to prosecution. This is considered normal practice and allows legitimate operators time to comply with the requests being made. All the while, however, more waste was arriving, with little or no compliance. Finally, later in 2009 the Environment Agency opted to begin prosecutorial action for non-compliance and remove their permits to process any further waste.

It is worth pointing out that in our view this particular Organised Criminal Group would have been aware of the lead in and overall timescale involved of any legal action; however, their illegal activity continued and the sites continue to fill as did their pockets. They did offer some legal challenge to the actions of the Environment Agency, maintaining that their activities were still legitimate, but one suspects that this was again nothing more than smoke and mirrors as part of delaying the legal process.
In July 2012, the Environment Agency successfully prosecuted the OCG on ten counts of illegal waste management. However, the sentencing was deferred as similar offences were still in process and the OCG members were released on strict bail conditions until all matters could be heard. During this time, the OCG, despite being convicted, continued to bring up legal challenges on the verdict and to maintain their innocence. And all the while the trucks continue to roll.

This posed a major dilemma for the Environment Agency. They had done everything within their power to stop this OCG from continuing their business, even successfully securing convictions, but were despondent at the OCGs continuing actions. Moreover, to compound things, this kind of crime is always something that the authorities have to play catch up on, once the damage is already done.

As a consequence of the above developments, the Environment Agency approached the Durham Police in September 2012 and asked for assistance to physically stop the continuing actions of the OCG. Parenthetically, the officer who was first requested to tackle this OCG (one of the co-authors) was on restricted duties and, therefore, was unable to face any confrontation or interact in the traditional way with members of the public at the time. Therefore, he only had a telephone, a computer screen and powers of persuasion to work with. One can speculate whether given a different personal situation he may not have decided on the route chosen to undermine the OCG.

Imagination was helpful as well. The officer had a lifelong interest in WW1 and, at this juncture, while he sat staring into the computer screen wondering how to tackle the OCG, he began to think of how the allies achieved success during WW1 and his thoughts were immediately taken to the Battle of Amiens, 1918. The battle of Amiens was short by the campaign standards of that time. Nonetheless, it was well conceived, planned and executed, achieving a seven-mile advance in 1 day. Considering that successes in WW1 were measured in yards rather than miles it had a profound effect and the tactics adopted then are still used to the present day. The reason why this campaign was a success was because it was the first time the allies had coordinated an attack using aerial power to spot and direct artillery. The artillery additionally utilised a creeping barrage while the advance followed some distance behind the shelter it was providing. Tanks led the assault with infantry following who were equipped with more automatic weapons than previously had been the case. The net result was a seven-mile gain during the first day.

Disrupting the OCG. Initial thoughts concerning the OCG followed this logic. The starting point was to scope their activity in full, examining all their activities to identify any wrongdoing that would assist in undermining their ability to function. Time was also spent identifying any 'Quick Wins'. This formed the basis of the strategy subsequently adopted.

By scoping the activity of the OCG, a number of anomalies were identified. The anomalies concerned different agenciessuch as local council planning breaches, utility companies and insurance providers. These formed the key agencies that were brought together to form a group to undermine the OCG. This was the beginning of a coordinated attack, with the key agencies representing the different limbs of the military in the battle of Amiens.

As previously mentioned, the OCG had been convicted and released on stringent bail conditions. One of the conditions was to cease any transfer of new waste into any of the sites. They continued to breach the condition; therefore, a number of covert operations were mounted to capture evidence that would 
eventually remand one of the principle members in jail while awaiting sentence.

Despite this success, the waste kept rolling in.

The next tactic was to examine the transport being used to continue their activity. The transport manager in this case had been a legitimate haulier up until the financial crash of 2008 that hit his business hard. He sold a number of vehicles and laid drivers off; however, provisions within his operator's licence allowed him to manage additional trucks. The OCG employed the transport manager at the outset of their venture because none of them fitted the criterion or qualification to perform the role. He was the next target for intervention.

As the transport manager, he was solely responsible for the activities of vehicles belonging to the OCG, vehicles which had been used to illegally transfer waste into the sites following convictions. Therefore, he had to provide a credible explanation for his actions. He was interviewed concerning his involvement and told that if he did not heed the warning and remove himself from this position then he would be relieved of his operator's licence. He assured the police that no further illegal operations would ensue.

Fortunately, around this time the convictions of the OCG had been widely publicised and appeared in the local newspapers with photographs, one of which clearly identified the registration number of one of their trucks. The scoping activity had identified the vehicle insurance company responsible for the OCG. This company was approached and alerted to the fact that they were in fact insuring convicted criminals who had no regard concerning any risk and liability that may come from their wrongdoing. This conversation prompted the insurance company to withdraw cover provided for the OCG. Now for the first time their transport activity stopped.

The transport manager was wise to suspend activity following the previous warning. Nonetheless, he went on to re-insure with a new insurer but failed to disclose that his previous insurer had revoked the policy. That was the next port of call. The new insurer was disclosed the same facts as before, with the addition of the transport manager's lies at the inception of the policy. The insurer withdrew cover and the whole thing started again with another insurer. Three times this occurred until no one would provide insurance cover or it was at a price well beyond what the OCG wished to pay. Additionally, and more importantly, the transport manager had by his actions lied on three occasions to the insurers to obtain cover, effectively committing fraud. Now there was an opportunity to remove him, effectively leaving the OCG without a transport manager or insurance cover. The operations stopped.

Now that there was a principle OCG member in prison, and with the transport manager withdrawn and being pursued for illegality, there was nobody to replace him and no insurance company offering to provide vehicle insurance. On the face of it this looked good, however, there were still two sites full of waste and no idea of by whom or when it might be cleared.

In May 2013, the principle member of the OCG was granted bail via a judge in chambers and within 1 week of his release one of the sites caught fire. Ten thousand tonnes of waste were alight which took 45 fire fighters 1 week to effectively bring under control. The problem now was dramatically heightened, with considerable public concern being expressed about the activities of the OCG. The local MP championed the constituents concerns and publicly announced that the enforcement agencies had sat on their hands and allowed the situation to develop. She was diplomatically informed that the agencies had done all in their power to prevent the activity of the OCG by conventional means and that they, along with the police, had now embarked on other methods as the criminal justice system had effectively not been able to address the issue. She became an ally and spokesperson, as well as provided political muscle when needed to oil the wheels of the agencies working to disrupt the OCG.

The dilemma now concerned the removal of 10,000 tonnes of smouldering waste that owing to its state could not be left; but to remove it at the public purse would have been unthinkable. Very detailed scoping identified the land owner, who turned out to be a cash rich individual and a principle OCG member. This individual had previously sat on the periphery of the OCG but more research revealed him as the brains behind the outfit. He had provided two of the sites to the OCG, outwardly appearing as the landlord, but he had also provided the money and means to set up the operation and was creaming off the money it had generated.

The OCG on paper had no identifiable budget and as such could not pay for any of the accumulated clearance costs. The landlord pleaded innocence and that he could not be held to account for the actions of his tenants. What he had not accounted for was the detailed analysis of his involvement that also identified wrongdoing on his part. He had purchased the land for one of the sites from a neighbouring company. The neighbouring company was aware that the land was to be used as a waste transfer station and as such included a caveat within the original contract of sale forbidding the storage of waste outside the building on the site. In the event, 90,000 tonnes of waste were sat outside the site. The plaintiff in this case, however, was fearful of reprisal and had not actioned the breach. The company concerned was approached by the police and reassured that all the key agencies involved would support their action if they brought the matter to Court.

In Newcastle County Court in July 2013 the plaintiff won against the OCG. There was a clear breach of contract and the Court ordered the clear up of the site within 3 months, total cost approximately $£ 500,000$, with $£ 62,000$ costs levied at the cash rich individual. At this the landlord and another principle OCG member began to fight in the foyer of the Court building. By September that year, one of the two sites full of waste was cleared at the cost of the OCG.

The second site was full of waste and therefore also of great concern as it, too, posed a substantial fire risk. The second site was also owned by the same landlord, but this time there was no breach of contract to force his hand to clear it up.

In this instance, another neighbouring company to the second site, a small engineering company contacted the police. The managing director informed the police that their insurers had expressed concern at the waste pile at the adjoining premises and that they were not prepared to offer any further cover without a substantial increase in premium due to the fire risk. She went on to say that as the company was working to very tight margins they only had three options: (1) move premises, not financially viable; (2) lay off staff to cover the increase in insurance premium; or (3) close. None of these options were acceptable, and it took hard work hard to secure insurance and reassure the insurance company that the waste would be removed. This was a separate story completely and one which concerned the insurance, and not the OCG directly. However, it does illustrate that a consequence of their wrongdoing was to put at risk local livelihoods. This is not an ideal situation.

Intense scoping of the second site commenced. The ideal situation would be that the cash rich landlord would be cited as being responsible for the clear up, as with the first site. After considerable consultation, it was identified that at the outset of the business the Local Authority had granted planning permission for the site to operate as a waste transfer station, but because of the previous wrongdoing the Environment Agency had removed permits allowing such activity. The site, therefore, had effectively become the final resting place of the waste and this was 


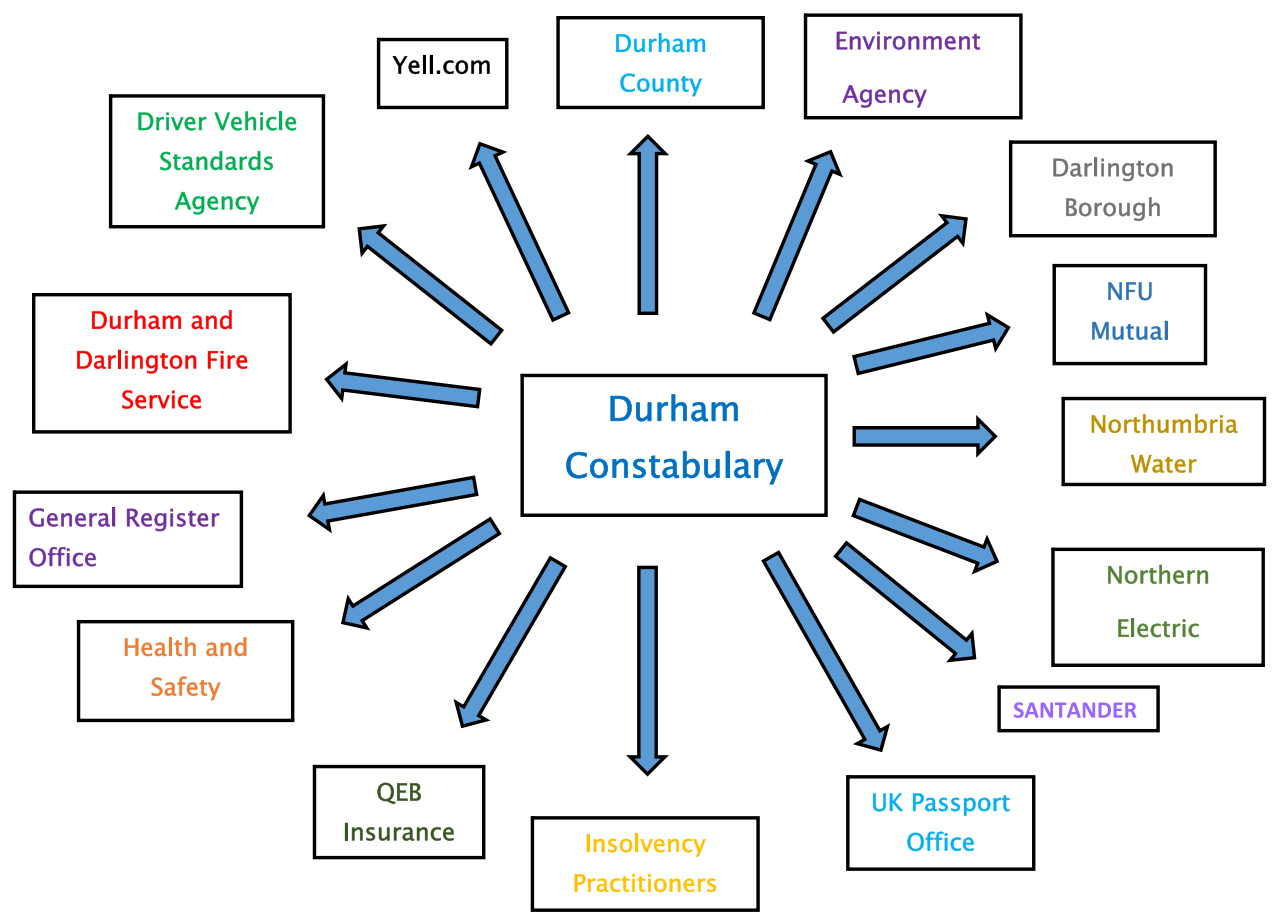

Fig. 1 Multi-agency collaborations with Durham constabulary

something that breached the planning regulation. The real nugget in this find was that it cited the landlord as well as tenant as being responsible for the clear up.

This action as well as the threat of some minor action taken by the Environment Agency against the landlord resulted in a deal being negotiated whereby the Environment Agency would stave off their prosecutions if the landlord cleared the site at his own expense. He had no choice as the planning regulations if pursued identified him as responsible for clear up cost plus the additional legal costs. He reluctantly agreed and cleared the site at an approximate cost of $£ 300,000$.

Nearby jobs were safeguarded and as such the local economy protected. There was also no option left for the OCG to set fire to the premises.

This was effectively the final straw. Members of the OCG were tried for the subsequent offences and some received custodial sentences. The transport manager had left, the company had been dissolved and the landlord had been left with considerable costs. The OCG was for all intents and purposes dismantled.

How was this achieved? The activity of the OCG was scoped in order to identify anomalies. A group of relevant stakeholders was organised to address those anomalies. Not only were these agencies best placed to address the anomalies none of them ever did anything alone. The agencies always acted in a coordinated manner with a common goal that was to undermine the ability of the OGC to function. This was not always focussed on prosecution but more towards disruption of the OCG activities.

\section{Multi-agency collaboration}

Detailed thick description of this case has demonstrated that investigative nous involving deep scoping of the Organised Criminal Group created an opportunity for innovative responses to the crimes associated with illegal waste dumping and stockpiling. An initial starting point was scoping the criminal targets to ascertain the nature and dynamics of the people and activities associated with the Organised Criminal Group. As part of this process, there was the equivalent of an environmental enforcement sweep (Dighe and Pettus, 2011), that is, lateral thinking directed at finding ways to disrupt the activities of the OCG across various administrative and legal fronts.

Collaboration was born out of necessity, since conventional criminal justice pathways had failed to secure environmental wellbeing. Those involved included local agencies and actors who worked in tandem to address the evils in their midst. Figure 1 outlines the many agencies that in some way were involved (although these were not all mentioned in the narrative above). Importantly, the coordination of these agencies was provided by the police who offered advice and enabled persistence. This centralised leadership and drive were essential to the eventual outcome.

Recent years have seen increased attention to and implementation of partnership approaches to addressing crime in the United Kingdom (Crawford and Cunningham, 2015; Berry et al., 2011; O'Neill and McCarthy, 2014). This has involved police working closely with a range of government and non-government agencies and stakeholders with the intent of developing innovative and diverse responses to crime. While there are pitfalls and limitations associated with these approaches (for example, where a strategy has multiple aims that reflect divergent interests), the present study reflects the potential success of such methods.

The notion of multi-agency collaboration refers to the engagement of a number of agencies working alongside one another to disrupt crime. It also refers to the utilisation of a range of tactics and strategies to disrupt environmental vandalism of the kind described above. It has been observed that in other jurisdictions this combination of partnerships and activities requires tools and approaches that are fit for purpose (Dighe and Pettus, 2011). In other words, each environmental crime case is different, and each requires its own tailor-made response. Yet, across diverse cases, similar principles of intervention can be applied.

Firstly, it is important that local area businesses, agencies and community groups be brought into the conversation about damaging environmental practices such as illicit dumping and storing of waste. The eyes and ears of a locality are its people, and its interests are also best protected when the community as a 
whole is on side and participating in preventing such harms. Meaningful participation takes several forms, from reporting of events through to cutting off of power and water due to unpaid bills. Information can come from many different quarters and this can be collated and applied by police (among others) to target the Organised Criminal Group in the most effective way.

Secondly, there is a range of measures that can be mobilised in tandem to disrupt local criminal activities. As the case example demonstrates, action taken around licensing and insurance, as well as criminal prosecution can be brought to bear upon OCGs. As indicated in Fig. 1, a myriad of agencies may have an interest in the individuals at the centre of police attention. The obligations of landholders in regards to site management and health and safety issues, as well as their ordinary obligations as residents and citizens, can provide important departure points for putting pressure on them-by neighbours, employees, associates and service providers-to desist from criminal activities. Gathering information across these domains can thus provide potential weak points to undermine present actions and prevent future ones. Again, a combination of administrative, civil and criminal enforcement tools can be mobilised, although the specific content and combination depends upon the players and the activities in question.

Thirdly, organised criminal groups and illicit networks have the advantage generally of flexibility and a good working knowledge of local conditions and actors, which facilitate the crimes in question. As described earlier, a NEST approach mirrors to some extent these attributes. It mobilises a broad range of actors, with varying types and levels of expertise, with local through to international connections, around single-purpose interventions. It has the capacity to provide 'eyes on the ground' as well as a 'bird's eye' view of commodity chains and criminal networks. Yet, at the local level, what seems more appropriate is a combination of informal and formal collaboration. In part, this stems from the notion that there is not a 'one size fits all' solution to specific crimes. Each crime and criminal group is different in some respects. Moreover, the commitment and interests of stakeholders will vary depending upon the matters at hand and the groups involved. While a general framework for multi-agency collaboration is useful-for example, a framework that outlines potential participants, procedures and policies-it would appear that ad hoc task forces and transient cooperation may well best match the needs of those at the local level. In other words, the driving force for collaboration ought to be what is needed in the here and now, rather than reliant upon bureaucratic requirement or structured inter-agency engagement (although the latter, too, have their place in regards to official government agencies).

\section{Conclusion}

As this article has illustrated, the disruption of environmental crime can proceed across several domains at once. Social, political, media, administrative and criminal justice actions all in their own way contributed to the result. Alliances were formed, and different agencies were involved in ways that reflected their tactical strengths-from insurance companies to politicians, police officers to officials from environmental protection. The project had a focus, and the participants zeroed in on the Organised Criminal Group using the approaches and tools at their disposal.

The message for environmental law enforcement is clear. Singularly each agency has limited impact and does not always address the issue of incapacitating the OCG's ability to function. By contrast, multi-agency work enables the authorities to work on a united front and thus to succeed in disrupting the criminal activities causing environmental harm. Interestingly, in this particular instance the police had a pivotal coordinating role, something that is not always the case when it comes to environmental crime (Nurse, 2015). Whether this is due to the singular personalities involved, the circumstances of the case, the fact that an organised criminal group was behind the environmental harm, encouragement from enlightened management, or a combination of these, is open to debate. Nonetheless, the case study provides an example of an exciting intervention model that, in this particular locale, proved highly successful in disrupting crime.

Received: 7 February 2017 Accepted: 6 September 2017 Published online: 24 October 2017

\section{References}

Ayling J (2013) What sustains wildlife crime? Rhino Horn trading and the resilience of criminal networks. J Int Wildl Law Policy 16(1):57-80

Berry G, Briggs P, Erol R, van Staden L (2011) The effectiveness of partnership working in a crime and disorder context: A rapid evidence assessment. London: Home Office. https://www.gov.uk/government/uploads/system/ uploads/attachment_data/file/116549/horr52-report.pdf.

Carnwell R, Carson A (2005) Understanding partnerships and collaboration. In: Carnwell R, Buchanan (eds) Effective practice in health and social care: A partnership approach. Open University Press, Maidenhead, p 3-20

Crawford A (2008) Plural policing in the UK: policing beyond the police. In: Newburn T (ed) Handbook of policing, 2nd edn. Willan Publishing, Devon, p 147-181

Crawford A, Cunningham M (2015) 'Working in partnership: the challenges of working across organizational boundaries, cultures and practices'. In: Fleming J (ed) Police leadership_rising to the top. Oxford University Press, Oxford, p 71-94

Dighe K, Pettus L (2011) Environmental justice in the context of environmental crime. United States Attorneys' Bull 59(4):3-14

Environment Agency (UK) (2017) Services and Information: Waste. EA, London

Faure M, De Smedt P, Stas A (eds) (2015) Environmental enforcement networks: concepts, implementation and effectiveness. Edward Elgar, Cheltenham

Higgins D, White R (2016) 'Collaboration at the front line: INTERPOL and NGOs in the Same NEST'. In: Pink G, White R (eds) Environmental crime and collaborative state intervention. Palgrave Macmillan, Basingstoke, p 101-116

INTERPOL (2012) National environmental security task force: Bringing compliance and enforcement agencies together to maintain environmental security. INTERPOL, Lyon

INTERPOL (2015) Environmental crime and its convergence with other serious crimes. INTERPOL, Lyon

INTERPOL \& UNEP (2016) Strategic report: Environment, peace and security a convergence of threats. INTERPOL, Lyon

Lemieux A (ed) (2014) Situational prevention of poaching. Routledge, London

National Crime Agency (UK) (2017) Home. NCA, London

Nurse A (2015) Policing wildlife: Perspectives on the enforcement of wildlife legislation. Palgrave Macmillan, Basingstoke

O’Neill M, McCarthy D (2014) (Re)negotiating police culture through partnership working: Trust, compromise and the 'new' pragmatism. Criminol Crim Just 14(2):143-159

Pink G, Bartel R (2015) Regulator Networks: Collaborative agency approaches to the implementation and enforcement of environmental law. In: Martin. P, Kennedy A (eds) Implementation of environmental law. Edward Elgar, Cheltenham, p 308-337

Pink G, White R (eds) (2016) Collaboration in combating environmental crime: making it matter. In: Environmental crime and collaborative state intervention. Palgrave Macmillan, Basingstoke, p 3-20

Pires SF (2012) The illegal parrot trade: a literature review. Glob Crim 13 (3):176-190

Pires S, Moreto W (2011) Preventing Wildlife Crimes: Solutions that can overcome the "tragedy of the commons". E J Crim Policy Res 17(2):101-123

Von Essen E, Hansen H, Kallstrom H, Peterson M, Peterson T (2014) Deconstructing the poaching phenomenon: A review of typologies for understanding illegal hunting. Br J Crim 54:632-651

Wellsmith M (2011) Wildlife crime: The problems of enforcement. Eu J Crim Policy Res 17(2):125-148

White R (2016) 'Reparative justice, environmental crime and penalties for the powerful'. Crime Law Soc Chang 67:117-132

White R, Graham H (2010) Working with offenders: A guide to principles and practices. Willan/Routledge, London 
White R, Heckenberg D (2011) Key vulnerabilities and limitations in the management of hazardous waste and its disposal: A checklist assessment tool. J Env Prot 2(9):1257-1263

White R, Heckenberg D (2014) Green criminology: An introduction to the study of environmental harm. Routledge, London

Wyatt T (2013) Wildlife trafficking: A deconstruction of the crime, the victims, and the offenders. Palgrave Macmillan, Basingstoke

\section{Data availability}

Data sharing is not applicable to this article as no datasets were generated or analysed during the current study.

\section{Additional information}

Competing interests: The authors declare no competing financial interests.

Reprints and permission information is available online at http://www.nature.com/ reprints

Publisher's note: Springer Nature remains neutral with regard to jurisdictional claims in published maps and institutional affiliations. (c) Open Access This article is licensed under a Creative Commons Attribution 4.0 International License, which permits use, sharing, adaptation, distribution and reproduction in any medium or format, as long as you give appropriate credit to the original author(s) and the source, provide a link to the Creative Commons license, and indicate if changes were made. The images or other third party material in this article are included in the article's Creative Commons license, unless indicated otherwise in a credit line to the material. If material is not included in the article's Creative Commons license and your intended use is not permitted by statutory regulation or exceeds the permitted use, you will need to obtain permission directly from the copyright holder. To view a copy of this license, visit http://creativecommons.org/ licenses/by/4.0/.

(C) The Author(s) 2017 